\title{
CaMKII Isoforms in Learning and Memory: Localization and Function
}

\section{OPEN ACCESS}

Edited by:

Sung Jun Jung,

Hanyang University, South Korea

Reviewed by:

Sajikumar Sreedharan,

National University of Singapore,

Singapore

Peter K. Giese,

King's College London,

United Kingdom

*Correspondence:

Arturo Romano

aromano@fbmc.fcen.uba.ar

${ }^{{ }^{P} \text { Present address: }}$

Noel Federman,

Laboratorio de Circuitos Neuronales, Instituto de Investigación en

Biomedicina de Buenos Aires Consejo Nacional de Investigaciones

Científicas y Técnicas - Partner Institute of the Max Planck Society,

Buenos Aires, Argentina

Received: 18 September 2018 Accepted: 19 November 2018

Published: 04 December 2018

Citation:

Zalcman G, Federman N and Romano A (2018) CaMKII Isoforms in Learning and Memory: Localization and Function

Front. Mol. Neurosci. 11:445. doi: 10.3389/fnmol.2018.00445

\author{
Gisela Zalcman ${ }^{1,2}$, Noel Federman ${ }^{1,2+}$ and Arturo Romano ${ }^{1,2 *}$ \\ ${ }^{1}$ Instituto de Fisiología, Biología Molecular y Neurociencias, Universidad de Buenos Aires - Consejo Nacional \\ de Investigaciones Científicas y Técnicas, Buenos Aires, Argentina, ${ }^{2}$ Departamento de Fisiología, Biología Molecular y \\ Celular, Facultad de Ciencias Exactas y Naturales, Universidad de Buenos Aires, Buenos Aires, Argentina
}

Calcium/calmodulin-dependent protein kinase II (CaMKII) is a key protein kinase in neural plasticity and memory, as have been shown in several studies since the first evidence in long-term potentiation (LTP) 30 years ago. However, most of the studies were focused mainly in one of the four isoforms of this protein kinase, the CaMKIll. Here we review the characteristics and the role of each of the four isoforms in learning, memory and neural plasticity, considering the well known local role of $\alpha$ and $\beta$ isoforms in dendritic terminals as well as recent findings about the $\gamma$ isoform as calcium signals transducers from synapse to nucleus and $\delta$ isoform as a kinase required for a more persistent memory trace.

Keywords: CaMKII, learning, memory, CaMKII $\alpha$, CaMKII $\beta$, CaMKII $\delta$, CaMKII $\gamma$

\section{INTRODUCTION}

CaMKII is one of the main effectors enzymes involved in calcium signaling in eukaryotic cells. The enzyme is activated as a result of increased intracellular calcium and phosphorylates target proteins involved in various processes such as mobilization of synaptic vesicles, modulation of ion channels, regulation of gene expression, regulation of muscle contraction, and LTP (Wu and McMurray, 2001; Lisman et al., 2012; Ojuka et al., 2012). Over the last two decades CaMKII has become one of the most studied proteins in the nervous system, and it has proven to be a key protein involved in learning, memory, and synaptic plasticity (Lisman et al., 2002, 2012; Irvine et al., 2006; Lucchesi et al., 2011; Coultrap and Bayer, 2012). CaMKII is a holoenzyme composed of 12 subunits of $56-60 \mathrm{kDa}$ that are assembled into 2 rings of 6 subunits each (Gaertner et al., 2004). Interestingly, these subunits are proteins encoded by four distinct but highly related genes termed camk2a, camk2b, camk2d, and camk2g, which give rise to four different CaMKII isoforms: $\alpha, \beta, \delta$, and $\gamma$. Each isoform has different calcium trapping kinetics, sub-cellular localization and affinity for other protein binding, thus enabling CaMKII to have different properties according to its subunit composition, which can be composed of a single type or a combination of isoforms (Srinivasan et al., 1994; Brocke et al., 1999). Furthermore, the RNAs that code for the different isoforms can undergo alternative splicing, resulting in the synthesis of approximately 30 different variants (Hudmon and Schulman, 2002). In the present review, we will first describe general features of CaMKII structure and mechanism of activation and then summarize the main features of each isoform and their splicing variants as well as our current understanding on their role in learning and memory. Studies focused on the interplay between subunit composition and functional outcome will not only contribute to understand why CaMKII is so fundamental for learning and memory processes but they might also reveal key information on the molecular mechanisms involved in memory storage. 


\section{CaMKII STRUCTURE AND MECHANISM OF ACTIVATION}

Each of the subunits that comprise CaMKII multimeric enzyme has a conserved structure among the different isoforms: an amino terminal catalytic domain, followed by a regulatory domain that contains a self-inhibitory region and a binding site for the $\mathrm{Ca}^{2+} /$ calmodulin (CaM) complex, a variable sequence and finally an associative (or oligomerization) domain in the carboxyterminal end which allows assembly between the different subunits (Figure 1A; Schulman et al., 1995; Coultrap and Bayer, 2012). The homology in the catalytic and regulatory domains between the different isoforms and variants of splicing is 89-93\%, the main differences between sequences are found within the variable domain (Hudmon and Schulman, 2002). The enzyme is expressed mainly in the brain, but also in the rest of the tissues. In some regions of the brain, such as the hippocampus, the protein levels reach up to $2 \%$ of total proteins (Erondu and Kennedy, 1985; Hudmon and Schulman, 2002).
The entry of calcium into the cell leads to the formation of the $\mathrm{Ca}^{2+} / \mathrm{CaM}$ complex, which binds approximately 34 calcium ions per $\mathrm{CaM}$ in a cooperative form (Hanson et al., 1994). This complex binds to the regulatory region of CaMKII and produces a conformational change, which not only leads to the phosphorylation of its substrates, but also to an inter-subunit, intra-holoenzyme autophosphorylation at threonine 286 in the $\alpha$ isoform and threonine 287 in $\beta, \delta$, and $\gamma$ isoforms. Autophosphorylation on this site prevents the enzyme to revert to its inactive conformation and decreases the dissociation rate of the bound CaM. Thus, autophosphorylated CaMKII can remain active even after the intracellular calcium levels decrease and therefore acquire autonomous and $\mathrm{Ca}^{2+}$ independent activity (Hanson et al., 1989, 1994; Hudmon and Schulman, 2002). Interestingly, this autonomous activity can persist even upon degradation or dephosphorylation of some subunits given they can be replaced and rephosphorylated by neighboring autophosphorylated subunits (Lisman et al., 2002; Irvine et al., 2006). The discovery of CaMKII mechanism of

A

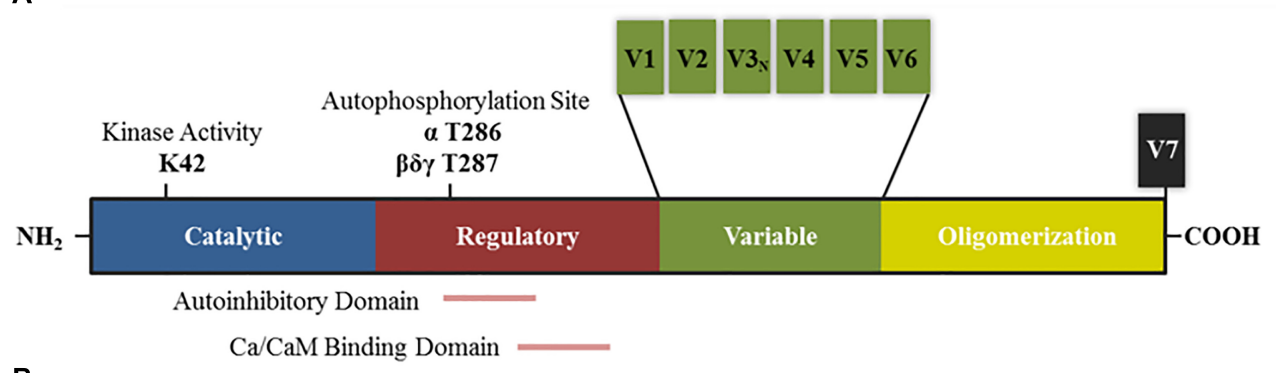

B

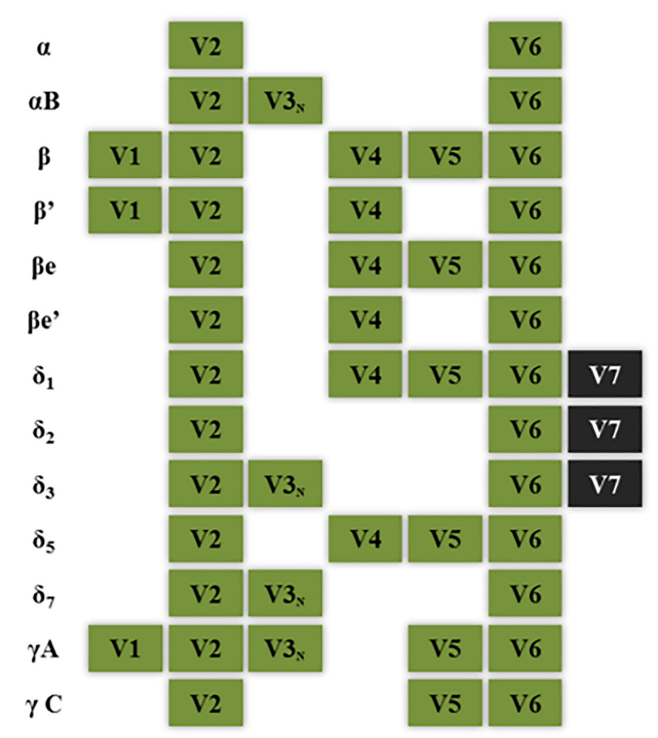

FIGURE 1 | Structure of CaMKII isoforms and splice variants. (A) General structure of CaMKII protein including the different functional domains and main key regulatory sites. K42 denotes the lysine residue that allows ATP binding. T286 and T287 are the threonine residues that are autophosphorylated upon calcium binding. Other sites not mentioned in the text are T305-T306 present in the Ca/CaM binding domain, which can be phosphorylated after CaMKII autophosphorylation and negatively regulates its activity by preventing further calcium binding (Coultrap and Bayer, 2012). (B) Splice variants for $\alpha, \beta, \delta$, and $\gamma$ isoforms that have been described in neurons. $V$ denotes variable region and $\mathrm{V}_{\mathrm{N}}$ represents the variable region containing the nuclear localization signal. "e" Denotes that these isoforms are expressed in embryonic stages (adapted from Tombes et al., 2003). 
activation resulted in an increasing interest from the learning and memory field in this enzyme. First, because of the ability to detect small variations in the concentration of intracellular calcium, as action potentials in neurons involve repeated pulses of calcium and memory formation is also tightly linked to the activation of calcium channels like NMDA and Cav1 (Morris, 2013; Berger and Bartsch, 2014). Second, because its singular ability to acquire persistent autonomous activity has been proposed as a form of molecular memory (Lisman et al., 2002). Indeed, subsequent studies have proven that CaMKII has a key role in memory as we will describe below.

\section{CaMKII AND MEMORY}

The activation of the NMDA receptor in glutamatergic excitatory pathways following a behavioral experience is key for long term memory (LTM) storage (Morris, 2013). This activation allows the entry of calcium into the neuron which binds to calmodulin to form the $\mathrm{Ca}^{2+} / \mathrm{CaM}$ complex that is recognized by multiple enzymes, thus inducing a molecular signaling cascade whose main function is to reshape the synaptic structure and physiology, together with regulation of gene expression necessary for the formation of LTM (Giese and Mizuno, 2013). CaMKII is one of the main targets of $\mathrm{Ca}^{2+} / \mathrm{CaM}$. Accordingly, CaMKII activity is increased upon learning and its inhibition causes LTM impairment (Tan and Liang, 1996; Lucchesi et al., 2011; for reviews see Cammarota et al., 2002). Learning to an inhibitory avoidance task increased hippocampal CaMKII activity up to 30 min after training (Cammarota et al., 1998). Studies in synaptic plasticity have shown that CaMKII activity after LTP induction seems to be increased only 1-2 min (Lee et al., 2009; Chang et al., 2017). This kinetics in CaMKII activity does not match that observed memory, suggesting that LTP may be regulated differently than memory formation. For instance, the longer kinetics observed in behaving animals experiments could suggest that memory formation may involve several "rounds" of LTP-like processes, and not just a single one.

To further understand the role of CaMKII in learning and memory processes different transgenic mice lines have been generated. Yasuda and Mayford (2006) developed a transgenic mouse line in which transgene expression of a constitutively active mutant form of CaMKII was inducible and limited to the superficial layers of medial entorhinal cortex, pre- and parasubiculum (Yasuda and Mayford, 2006). The transgene was constitutively expressed and could be inhibited after the administration of doxycycline. Learning to find a visible platform in a water maze was similar across trials between wild-type and transgenic mice, however, long-term memory formation of the platform location, as assessed in a testing session $24 \mathrm{~h}$ after training, was impaired in transgenic animals. Mice were also trained to novel object recognition task, and transgenic mice showed recognition memory impairment when tested $3 \mathrm{~h}$ after training, thus short-term memory storage for this non-spatial task was also impaired. Finally, using doxycycline to inhibit transgene expression, they performed two different experiments: (i) transgene was expressed immediately after testing to the water maze task and up to 3 weeks after, (ii) transgene was expressed $3-$ 6 weeks after training. These allowed studying the role of CaMKII activity after long-term memory consolidation. In the first case memory was impaired when tested 6 weeks after, suggesting that manipulating CaMKII activity affected the maintenance of the memory trace. In the latter, memory was not affected when tested 6 weeks after, indicating that at longer retention periods memory may have undergone systems consolidation and could be allocated in other cortical structures. More recently, a genetically encoded light-inducible inhibitor of CaMKII, called paAIP2, was designed, which allowed a tight temporal control on the manipulation of CaMKII activity. Mice received an intraamygdala injection of a virus containing the vector for the expression of paAIP2 and were implanted an optic fiber guided to the amygdala. Inhibiting CaMKII activity during doubletrial training to an inhibitory avoidance task led to memory impairment when tested $1 \mathrm{~h}$ after. Its inhibition immediately after training had no effect on memory when tested $1 \mathrm{~h}$ after training. From these results the authors concluded that CaMKII activity in the amygdala during training, but not after, is necessary for memory formation. It should be noted that, since the testing session took place $1 \mathrm{~h}$ after training, they evaluated short-term and not long-term memory storage (Murakoshi et al., 2017).

CaMKII binds to numerous proteins in the post-synaptic density (PSD), including NMDA receptor, synapsin 1, F-actin, and calcium channels. Presumably, the binding and phosphorylation regulates autonomous activity, location and/or transport of these and other proteins to regions of interest (Lucchesi et al., 2011; Sanhueza and Lisman, 2013; Hell, 2014). CaMKII can also regulate the number of AMPA receptors, together with their conductance, promoting the rapid growth of dendritic filopodia and spine formation (Jourdain et al., 2003; Lucchesi et al., 2011; Giese and Mizuno, 2013).

An important issue regarding neural plasticity and memory is the role of CaMKII in synaptic tagging and capture (STC) and behavioral tagging. STC is one of the proposed mechanisms that explain how the plasticity-related proteins (PRP) act only in the activated synapses by means of an activity dependent tag that allows the capture of PRPs in these specific synapses. CaMKII have been proposed as a tag mechanism for LTP (Sajikumar et al., 2007) and for long-term depression (LTD) (Szabó et al., 2016). In relation with the first finding, Redondo et al. (2010) found that the tag in LTP is sensitive to CaMKII inhibition. Such tagging function of CaMKII is transient and is then replaced by a PKM $\zeta$-mediated mechanism dependent on ryanodine receptor or synaptic activation of metabotropic glutamate receptors that prolongs the durability of the synaptic tag (Li et al., 2012). In studies with behaving animal the learning tag is setting by activation of the glutamatergic NMDA receptors and this machinery further required CaMKII and PKA but not ERK1/2 protein kinase activity (Moncada et al., 2011).

\section{CaMKII ISOFORMS}

$\delta$ and $\gamma$ are isoforms are expressed in different tissues including the brain while $\alpha$ and $\beta$ isoforms are brain 
specific (Bennett et al., 1983; Tobimatsu and Fujisawa, 1989). The studies on each isoform allow distinguishing differences and similarities in their affinity for calcium, their location and function. For instance, affinity for calmodulin and the rate of autophosphorylation between the different isoforms is estimated to be $\gamma>\beta \sim \delta>\alpha$ and $\delta>\beta>\alpha>\gamma$, respectively (Gaertner et al., 2004). Moreover, all the isoforms contain different splicing variants which have different sub-cellular localization and protein binding affinity, and thus even if the holoenzyme is only composed of subunits from a same isoform (homomeric), its overall features and function will depend on the properties of the variants that contains (Srinivasan et al., 1994).

\section{CaMKII $\alpha$}

CaMKII $\alpha$ contains three variants termed $\alpha, \alpha B$, and $\alpha \mathrm{KAP}$, the first two are abundant in the brain while the last one is expressed in skeletal muscle (Hudmon and Schulman, 2002). The $\alpha \beta$ variant contains a nuclear localization signal (NLS) which is also shared with variants of the $\delta$ and $\gamma$ isoforms, and is liable to regulation (Figure $\mathbf{2 A}$ ). The mRNA for $\alpha$ variant is expressed throughout the brain, while $\alpha_{B}$ mRNA is restricted to diencephalon/midbrain regions. Immunohistochemical studies performed in rat brain revealed that indeed, in thalamic and hypothalamic neurons which express both variants, CaMKII $\alpha$ protein localizes to the nucleus and the cytoplasm, while in caudate putamen, in which only the $\alpha$ variant is expressed, CaMKII $\alpha$ was exclusively seen in the cytoplasm (Brocke et al., 1995). The $\alpha$ KAP variant lacks the catalytic domain but contains a domain that facilitates its binding to the sarcoplasmic reticulum and a NLS, although its sub-cellular localization is mainly ruled by the membrane targeting sequence (Hudmon and Schulman, 2002), serving as an anchoring protein of catalytic competent subunits to membranes.

In neurons, CaMKII $\alpha$ localizes in pre-synapses and dendrites and is actually one of the main proteins in the PSD (Griffith et al., 2003; Liu and Murray, 2012). Its location in PSD is calciumdependent and it has been shown to be induced after NMDA (but not AMPA or metabotropic glutamatergic) receptor stimulation and is regulated by CaMKII $\beta$ F-actin binding (Shen and Meyer, 1999; Ahmed et al., 2006, see also CaMKII $\beta$ section). Also it is almost exclusive of synapses receiving glutamatergic terminals (Liu and Jones, 1996, 1997; Liu and Murray, 2012). In cultured hippocampal neurons expressing a mutant form of CaMKII $\alpha$ with impaired kinase activity or T286 autophosphorylation, PSD translocation after glutamate stimulation was not altered compared to CaMKII $\alpha$ wild type, and a CaMKII mutant that simulates the autophosphorylated state did not localize to PSD before stimulation, suggesting that neither kinase activity nor autophosphorylation are necessary for CaMKII $\alpha$ translocation to PSD. However, it was shown that after external calcium and glutamate removal the mutant $\mathrm{CaMKII} \alpha$ with impaired autophosphorylation dissociated more rapidly from the PSD than CaMKII $\alpha$ wild type (Shen and Meyer, 1999). Thus neither kinase activity nor T286 autophosphorylation are necessary for PSD translocation, but the later can regulate the process.

Of particular interest is a 30 nucleotide sequence present in the $3^{\prime}$ UTR of the CaMKII mRNA that targets it to dendrites, where it is locally translated (Figure 2B; Mayford et al., 1996). Its transport is inhibited in a resting state and is activated upon neuronal depolarization and NMDA receptor stimulation (Mori et al., 2000; Blichenberg et al., 2001; Néant-Fery et al., 2012). These particular characteristics and the fact that the PSD is a key compartment for the molecular events that subserve memory storage turned CaMKII $\alpha$ to be the most studied isoform in the field of neurobiology of memory.

\section{ROLE OF $\alpha$ ISOFORM IN MEMORY}

Different CaMKII $\alpha$ mutant mice have been generated, including homozygous and heterozygous knock out (KO) mice (Silva et al., 1992a,b, 1996), KI mice with impaired $\mathrm{Ca}^{2+} / \mathrm{CaM}$ binding (Elgersma et al., 2002), KI mice with a mutation blocking the catalytic activity of CaMKII $\alpha$ (Yamagata et al., 2009), KI mice with a mutation in T286 impeding autophosphorylation (T286A) (Giese et al., 1998) and transgenic mice expressing a mutated form of CaMKII $\alpha$ that can be rapidly and reversibly inhibited after the administration of a synthetic

\section{A}

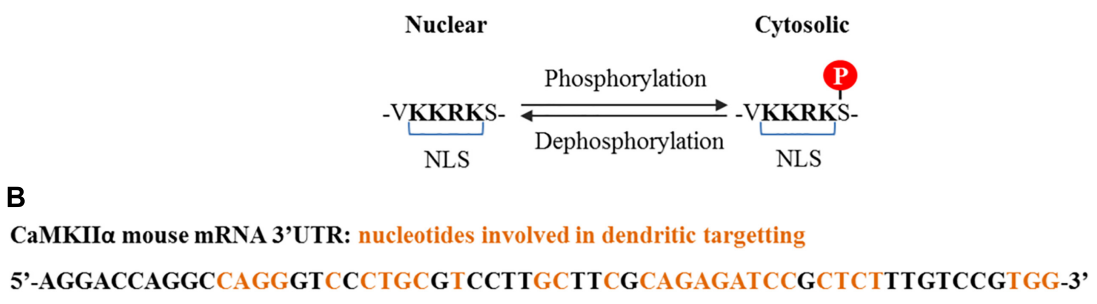

FIGURE 2 | CaMKIl $\alpha$ nuclear localization signal and dendritic mRNA location sequences. (A) Nuclear localization signal contained by some splice variants from $\alpha, \delta$, and $\gamma$ isoforms. Nuclear translocation is regulated by phosphorylation at the serine adjacent to the NLS. Phosphorylation at this serine by CaMKI and CaMKIV prevents CaMKIl $\alpha$ and CaMKII nuclear translocation (Heist et al., 1998), whereas dephosphorylation, presumably by PP2A for CaMKII $\delta$ and PP2B (calcineurin) for CaMKIl $\gamma$, promotes translocation (Zhang et al., 2002; Ma et al., 2014). (B) Common cis elements that have been shown to be involved in CaMKIll dendritic mRNA location and which are conserved among rat, mouse, and human (Mori et al., 2000). 
inhibitor (Wang et al., 2003). The effects of these and other mutations on memory and synaptic plasticity has been reviewed in Elgersma et al. (2004), Irvine et al. (2006), and Giese and Mizuno (2013), here we will present the main findings.

Homo and heterozygous $\mathrm{KO}$ mice showed learning impairment in several hippocampal-dependent tasks which could be sometimes overcome with extended training (Silva et al., 1992a; Yamasaki et al., 2008). However, these transgenic animals had the side effect of showing abnormal behavior, including altered locomotors activity and anxiety-like behavior, as well as an increased targeting of Cambia to PSD which could be compensating for the loss of CaMKII $\alpha$ (Elgersma et al., 2004; Yamasaki et al., 2008). Subsequent studies were done in transgenic mice bearing knock-in mutations on different key regions of the endogenous CaMKII $\alpha$ gene. KI transgenic mice that express a form of CaMKII $\alpha$ lacking its kinase activity showed learning and consequent memory impairment in a one-trial inhibitory avoidance task, while KI animals with impaired autophosphorylation at T286 had learning and memory impairments in one-trial passive avoidance tasks, the water Morris maze and contextual fear conditioning (Giese et al., 1998; Irvine et al., 2005; Yamagata et al., 2009). Learning impairment could be overcome with repeated training and, in the case of animals with impaired autophosphorylation at T286, this also rescued memory deficits (it should also be noted that in these animals CaMKII $\mathrm{Ca}^{2+}$-independent activity was reduced by $60 \%$ but not completely, so there could be some compensatory effect from the activation of other isoforms). Thus, it was proposed that autophosphorylation at T286 could be related to one-trial learning and not necessarily to memory storage (Giese and Mizuno, 2013). Regarding the need of CaMKII $\alpha$ activity in memory storage, it has been shown to be necessary for inhibitory avoidance LTM formation even after repeated training. On the other hand, heterozygous $\mathrm{KO}$ mice showed normal contextual fear conditioning learning and LTM 13 days after training but this was severely impaired at longer retention delays, when memory becomes independent of hippocampal processing and becomes dependant on storage in the cortex. Therefore, these results suggest a role of cortical CaMKII $\alpha$ in systems consolidation (Frankland et al., 2001, 2004).

In non-transgenic animals it has been shown that CaMKII $\alpha$ expression is also regulated in different types of learning and brain structures. For instance, in the hippocampus, a gene screening (coda array) showed that CaMKII $\alpha$ mRNA was upregulated $3 \mathrm{~h}$ but not $24 \mathrm{~h}$ after one-trial inhibitory avoidance training and its protein levels were increased $24 \mathrm{~h}$ but not $3 \mathrm{~h}$ after training (Igaz et al., 2004). In the dentate gyrus, western blot analysis revealed that object-place recognition learning triggered an increment in CaMKII $\alpha$ protein expression $1 \mathrm{~h}$ after training. In the striatum, permanent inhibition of CaMKII $\alpha$ expression after the stereotaxical injection of a lentivirus expressing a shRNA before training impaired accelerating rotarod and water cross maze test performances. However, these animals were able to learn properly after consecutive training similarly to what it has been seen for transgenic animals (Wang et al., 2017).

A key feature of CaMKII $\alpha$ relies on its local translation in dendrites. Regarding the role of this process in memory, it has been shown that when the mRNA was confined to the soma by mutation of the $3^{\prime}$-untranslated region in mice, LTM, but not short term memory nor learning, was impaired in cued and contextual fear tasks, water Morris maze and an olfactory associative task (Miller et al., 2002; Néant-Fery et al., 2012). These results point to an important role of CaMKII $\alpha$ local translation in LTM formation.

Altogether, these findings support that CaMKII $\alpha$ proper catalytic activity and T286 autophosphorylation are important for enabling fast learning, that its gene expression is involved in memory consolidation and that this protein may also have a role in remote memory formation.

\section{CaMKII $\beta$}

CaMKII $\beta$ isoform possesses six splicing variants (Figure 1). The ones that have been described in the brain are $\beta, \beta^{\prime}, \beta$ e and $\beta^{\prime} \mathrm{e}$ (Brocke et al., 1995; Hudmon and Schulman, 2002; O'Leary et al., 2006; Cook et al., 2018). A recent publication has also described the existence of a new variant expressed in the brain which was termed $\beta \mathrm{H}$ (Cook et al., 2018). None of the splice variants contain a NLS and this could explain why this isoform has not been shown to be present in the nuclear compartment.

The $\beta$ and $\beta^{\prime}$ variants contain an F-actin binding domain and are therefore, able to bind F-actin in basal conditions. Glutamate postsynaptic stimulation induces CaMKII $\beta / F$-actin release and subsequent PSD localization. The dissociation process requires binding of $\mathrm{Ca}^{2+} / \mathrm{CaM}$ to CaMKII $\beta$ and/or autophosphorylation at T287 and is not dependant on CaMKII $\beta$ kinase activity (Shen and Meyer, 1999; Lin and Redmond, 2008). Mutated forms of CaMKII $\beta$ with impaired calmodulin binding could bind to F-actin in basal conditions but were unable to dissociate after stimulation. A mutated CaMKII $\beta$ which mimic the autophosphorylation state could not bind to F-actin. Thus F-actin binding requires the enzyme to be in a non-autophosphorylated state (not active) and its dissociation requires $\mathrm{Ca}^{2+} / \mathrm{CaM}$ binding. CaMKII $\beta$ is usually associated with CaMKII $\alpha$ to form the heterozyme $\alpha / \beta$-CaMKII which translocates jointly to the PSD. Interestingly, translocation kinetics is dependent on the ratio of $\alpha / \beta$ subunits in the heteromer (Shen and Meyer, 1999). It has also been proposed that the $\delta$ and $\gamma$ isoforms can bind F-actin in vitro (Hoffman et al., 2013). Binding of CaMKII $\beta$ to F-actin has been shown to increase F-actin stabilization and bundling (O’Leary et al., 2006; Okamoto et al., 2007; Lin and Redmond, 2008; Sanabria et al., 2009) and was proposed that CaMKII $\beta$ transient dissociation from F-actin promotes actin re-organization which impacts in dendritic spine remodeling (Okamoto et al., 2007; Giese and Mizuno, 2013). Figure 3 summarizes CaMKII $\beta$ and $\alpha$ molecular dynamics in the PSD.

CaMKII $\beta$ has been implicated in a process of inverse synaptic tagging, targeting of Arc to inactive synapses via a high-affinity 


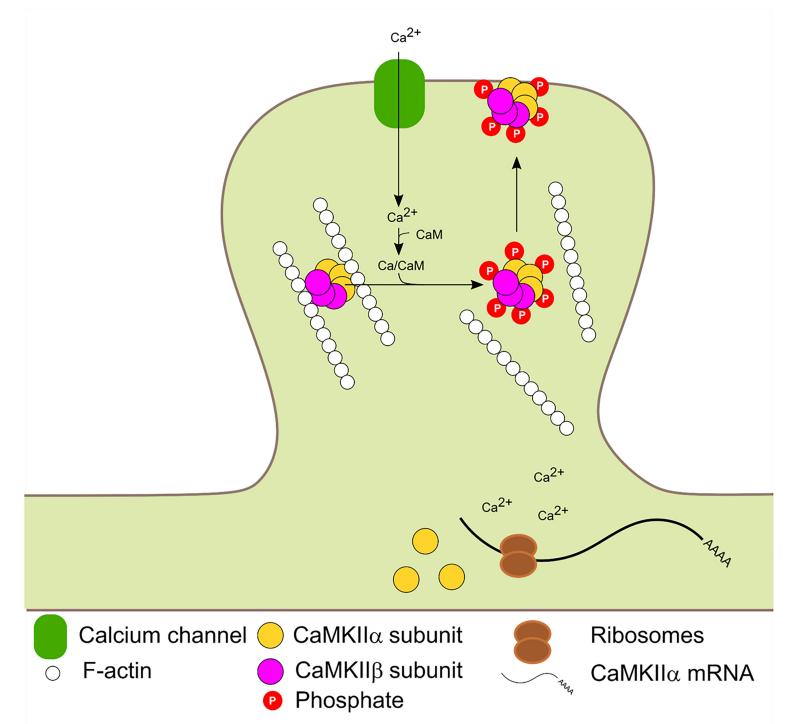

FIGURE 3 | Activity dependent PSD translocation and CaMKIl $\alpha$ dendritic translation. Synaptic activity leads to $\mathrm{Ca}^{2+}$ influx. Subsequent $\mathrm{Ca}^{2+} / \mathrm{CaM}$ binding to CaMKIl $\alpha$ and $\beta$ induce F-actin dissociation, translocation to the PSD and autophosphorylation at T286 and T287 in $\alpha$ and $\beta$ isoforms, respectively. Calcium entry also enhances local CaMKIl $\alpha$ mRNA translation.

interaction with the $\beta$ isoform that is not bound to $\mathrm{Ca}^{2+} / \mathrm{CaM}$ (Okuno et al., 2012).

\section{ROLE OF $\beta$ ISOFORM IN MEMORY}

A transgenic mice line was developed which expressed a mutated form of CaMKII $\beta$ whose activity could be reversibly inhibited upon the administration of a synthetic inhibitor (Cho et al., 2007). This over-expression of CaMKII $\beta$ led to an increase in its enzymatic basal activity. In the hippocampus, CaMKII $\beta$ overexpression was seen exclusively in the dentate gyrus. Learning and 1 day retention for novel object recognition task, cued and contextual fear conditioning were normal, but in this last task, 10 days retention was impaired (Cho et al., 2007). These animals also presented reversal learning deficits in the radial arm maze task and the water cross maze (Yin et al., 2017). Upon administration of the synthetic inhibitor at different time points before and after training, the authors could further conclude that the 10-day memory impairment was a consequence of increased CaMKII $\beta$ expression during the LTM consolidation phase, and not during acquisition or recall. The fact that the memory deficit was observed 10 days but not $24 \mathrm{~h}$ after training indicates that CaMKII $\beta$ activity during consolidation modulates the persistence of the memory that is being consolidated. On the other hand, two KO mice for CaMKII $\beta$ were developed, which differed in the locus in which a neomycin cassette was inserted to disrupt CaMKII $\beta$ gene sequence, and where later used to study the role of CaMKII $\beta$ in memory (van Woerden et al., 2009; Bachstetter et al., 2014). In one of these studies, animals showed impairment in novel object recognition when tested $4 \mathrm{~h}$ after training, suggesting CaMKII $\beta$ could be involved in short-term memory formation. These animals also showed differences compared to wild type in rotarod tests, balance beam and running wheel tasks, elevated plus maze and open field and they had altered body mass composition, among others traits (Bachstetter et al., 2014). In another of this studies KO mice showed impaired fear conditioning memory when tested $24 \mathrm{~h}$ after training (Borgesius et al., 2011). Interestingly, in this last work the authors found that CaMKII $\alpha$ expression levels were not altered in the CaMKII $\beta$ KO mice but its location to synapses was decreased by a $40 \%$. This prompted the authors to study if the memory deficits were a side-effect of decreased CaMKII $\alpha$ localization in PSD. To test this they used a KI mouse line in which $\mathrm{Ca}^{2+}$-dependent activation is blocked by interfering with $\mathrm{Ca}^{2+}$ binding, thus in these animals CaMKII $\beta$ can bind to F-actin but cannot be activated. Fear conditioning performance was normal in these animals and CaMKII $\alpha$ abnormal distribution was not seen. This last result led to the important conclusion that CaMKII $\beta$ binding to F-actin but not its catalytic activity is necessary for memory processes and CaMKII $\alpha$ translocation to spines.

Little is known regarding CaMKII $\beta$ expression changes in memory processes. In the striatum, it has been shown that CaMKII $\beta$ mRNA expression was up-regulated specifically after extensive training to an accelerated rotarod task, suggesting a delayed effect of training on CaMKII $\beta$ expression (D'Amours et al., 2011).

Altogether, these results suggest that $\beta$ isoform has a nonenzymatic role in LTM consolidation. Presumably a key function of this enzyme is to allow CaMKII $\alpha$ translocation to the PSD. However, the activity-dependent dissociation to F-actin seems to be important to regulate actin dynamics that may allow dendritic spine plasticity and synaptic reorganization (Okamoto et al., 2007; Hotulainen and Hoogenraad, 2010; Lamprecht, 2014). This fact could explain why manipulating CaMKII $\beta$ activity during the consolidation phase can affect memory persistence several days after, as seen in Cho et al. (2007).

\section{CaMKIII}

The $\delta$ isoform is expressed ubiquitously. To date, 13 different variants have been identified from alternative splicing of the gene which are expressed differentially in the brain, heart, and skeletal muscle. The structures of 10 of these variants have been studied in detail and show that the main difference between them is within two variable regions located next to the regulatory domain and the C-terminal end of the association domain, respectively (Mayer et al., 1993, 1995; Zhang and Brown, 2004; Figure 1B). The variants 1, 2, 3, 5, and 7 have been shown to be expressed in the brain (Schworer et al., 1993; Kamata et al., 2006). Interestingly, the variants 3 and 7 contain a NLS which is conserved with the isoforms $\alpha$ and $\gamma$ (Srinivasan et al., 1994). The expression of 2, 3, and 7 variants are highly abundant in heart tissue, where they have been shown to be involved in ischemia/reperfusion injury and the activation of NF- $\kappa$ B signaling cascade (Gray and Heller Brown, 2014; 
Gray et al., 2017). A recent publication has shown that this kind of injury in the brain also triggers a similar signaling cascade (Zhang et al., 2012). In brain, CaMKII protein has been shown to be present in the nucleus of cerebellar granule cells and substantia nigra dopaminergic neurons in rats (Takeuchi et al., 1999; Kamata et al., 2006). It has been proposed that CaMKII $\delta$ nuclear translocation in neurons is promoted by PP1-dependent dephosphorylation at Ser 332 enhancing BDNF transcription (Kamata et al., 2006; Shioda et al., 2015). More recently, we found the $\delta$ isoform in mice hippocampal pyramidal cells, with an important presence in nuclei (Zalcman et al., 2018).

We recently found in the hippocampus that CaMKII $\delta$ is also located in pre-synaptic terminals. Even though strong evidence points to a crucial role for hippocampal pre-synaptic CaMKII in synaptic plasticity and neurotransmitter release (Jovanovic et al., 2001; Ninan and Arancio, 2004; Lu and Hawkins, 2006; Wang, 2008), little is known about the presence of each isoform in this compartment. The presence of CaMKII $\delta$ in axons has been documented during neuronal development. Effectively, CaMKII $\delta$ is the main isoform present in the axons of developing rodent neurons, related with neurite outgrowth and stability (Donai et al., 2000; Johnson et al., 2000; Faison et al., 2002; Easley et al., 2006).

\section{ROLE OF $\delta$ ISOFORM IN MEMORY}

Until recently, the role of CaMKII $\delta$ in memory processes was virtually unknown. In a first study from our laboratory, we showed that training to a Novel Object Recognition (NOR) task induced NF- $\kappa \mathrm{B}$ binding and histone acetylation in the promoter of $\delta$ isoform gene as well as an increase in its expression $3 \mathrm{~h}$ after training (Federman et al., 2013). NF- $\kappa \mathrm{B}$ is a key transcription factor for long-term memory consolidation (Alberini, 2009; Romano, 2012; de la Fuente et al., 2015). Histone acetylation is a molecular process that enhances gene expression and is also related to memory strength and persistence (Federman et al., 2013, 2014; Kim and Kaang, 2017). This first evidence led us to the hypothesis that CaMKII $\delta$ gene expression could be sustained beyond memory consolidation in order to warrant memory persistence. More recently, we found that, indeed, training to a NOR task increased CaMKII $\delta$ mRNA levels several days after training (Zalcman et al., 2018). Its expression was increased up to 7 days while memory retention was present, and returned to basal levels 20 days after, when recognition memory retention was vanished. These results suggest that CaMKII $\delta$ expression parallels memory retention. This persistent gene expression was also accompanied by long-term changes in nucleosome dynamics on key sites of its promoter, further supporting the presence of longterm molecular events to regulate its expression. Such a sustained gene expression after learning has been rarely reported, with the exception of PKM $\zeta$, a protein that has been shown to be upregulated up to 7 days after training in the insular cortex (Shema et al., 2011) and for 1 month in the hippocampus (Hsieh et al., 2016). Therefore, has been proposed to participate in memory maintenance. In accordance with these findings, inhibiting CaMKII $\delta$ gene expression $24 \mathrm{~h}$ after NOR training, once memory has been consolidated, led to memory impairment at day 7 , suggesting that CaMKII $\delta$ is indeed involved in mechanisms that affect maintenance of the memory trace. The fact that inhibition of CaMKII $\delta$ gene expression during consolidation affect memory at 7 days but left 1 day memory intact support a specific action in persistence and maintenance. Previous evidence has implicated CaMKII activity in memory maintenance. In a recent publication it was shown that transient hippocampal expression of an inactive form of CaMKII 3 days after training, once memory is supposed to have been consolidated, affected behavioral performance when tested 9 days after training, a time point in which virally mediated protein expression had ended (Rossetti et al., 2017). On the other hand, it was also shown that the expression of a constitutively active mutant form of CaMKII in parahippocampal regions, during the first 3 weeks after training to a water maze task, affected the maintenance of a previously established spatial memory (Yasuda and Mayford, 2006). On the contrary, inhibiting CaMKII activity $24 \mathrm{~h}$ after training to an inhibitory avoidance task, had no effect on a behavioral test performed $1 \mathrm{~h}$ after the inhibition (Buard et al., 2010). This last result, taking into account the previous two, suggest that while CaMKII activity may be necessary for memory maintenance, it may not have an immediate impact on the memory trace, thus the impairment may be observable several days after the manipulation.

Interestingly, whilst it is not common to observe sustained gene expression for most proteins, this seems to be a feature of CaMKII $\delta$. It has been shown that CaMKII $\delta$ protein expression can be increased up to 5 days after brain injury in rats (Zhang et al., 2012) and up to 7 days in homogenates form ventricles after transverse aortic constriction (Zhang et al., 2003). CaMKII $\delta$ mRNA was also up-regulated 7 and even 21 days after nerve injury in the peripheral system (Xiao et al., 2002; Bangaru et al., 2015). Moreover, what it is remarkable from our results is not only the novelty on CaMKII $\delta$ involvement in memory persistence, but also that it poses two novel molecular mechanisms by which a memory trace is allowed to persist on time: sustained gene expression and nucleosome positioning dynamics. Figure 4 summarizes our findings and proposes a general mechanism by which a stronger training favors the formation of a more persistent memory trace.

At this point two key questions arise. First, in which way is CaMKII $\delta$ gene expression functional to memory maintenance? A maintenance molecular mechanism should be sustained over time and should be necessary for memory retention beyond the consolidation time window. In this report we provide evidence that support this role for CaMKII $\delta$. In addition, such mechanism should be involved in synaptic efficacy modifications. The action of CaMKII $\delta$ in pre-synapses of excitatory pathways could determine an increment in neurotransmitter release (Wang, 2008) and its action in the nucleus could regulate epigenetic mechanisms and transcription of effectors genes. In cardiomyocytes nuclear translocation of CaMKII $\delta$ has been shown to regulate histone $\mathrm{H} 3$ phosphorylation at serine 10. Besides, it induces histone deacetylase HDAC4 export to the cytoplasm, increasing gene transcription (Zhang et al., 2007; Awad et al., 2015). Notably, both H3 phosphorylation and HDAC4 have been 
A
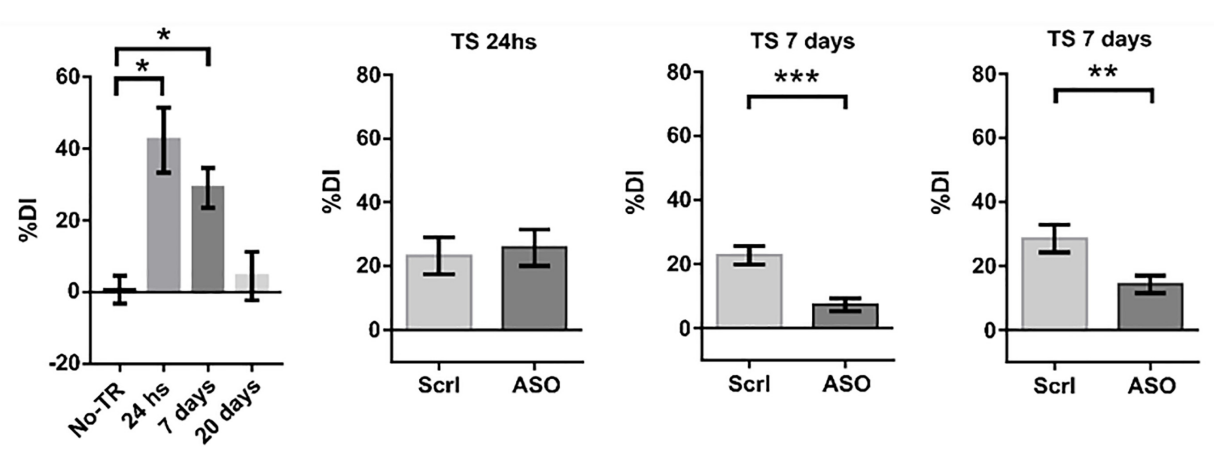

B
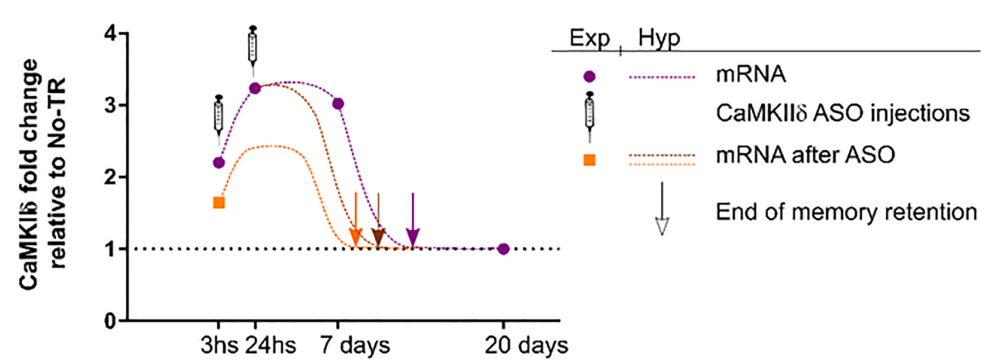

c

No-TR

$1 \mathrm{~h}$

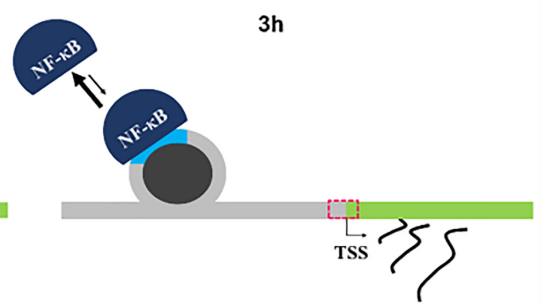

20 days
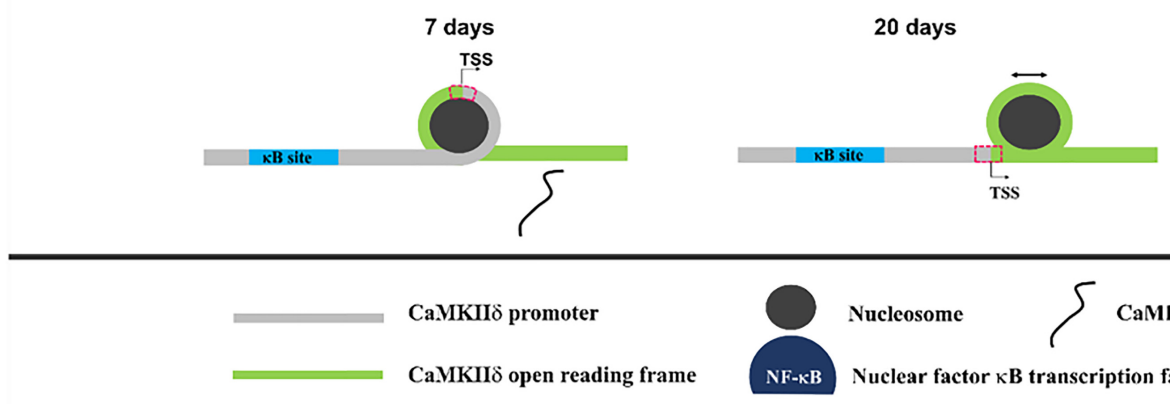

Nucleosome

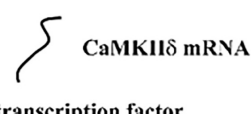

Nuclear factor $\kappa \mathrm{B}$ transcription factor

FIGURE 4 | CaMKIII role in memory persistence. (A) Left graph shows mice performance $24 \mathrm{~h}, 7$ days, and 20 days after training to Novel Object Recognition task compared to non-trained animals (No-TR). Performance is expressed as a discrimination index (\%DI) that is an indicator of the time spent exploring a novel object over a familiar one (Zalcman et al., 2018). Note that memory retention decays with time and is significantly above the control group when animals are tested $24 \mathrm{~h}$ and 7 days after training. Infusion of an oligonucleotide antisense to CaMKIII mRNA (ASO), which effectively decreases CaMKIII expression, $2 \mathrm{~h}$ after training leads to memory impairment when animals were tested 7 days after but not $24 \mathrm{~h}$ (middle graphs). Seven days memory impairment was also found when CaMKIII ASO was injected $24 \mathrm{~h}$ after training (right graph). Scrl: scrambled oligonucleotide used as a control (with permission of Springer Nature). (B) Graph showing the mRNA levels for CaMKIII measured experimentally at different time points after training and after ASO administration (purple circles and orange square, respectively) together with a hypothetical curve (dash lines). Based on our results, we propose that memory can be recalled as long as CaMKIII mRNA levels are above basal condition. Arrows indicate a hypothetical time point at which CaMKIII mRNA return to basal levels and thus memory retention is lost. ASO administration shifts mRNA curve in such a way that only 7 days memory is affected. (C) Nucleosome occupancy on $\mathrm{kB}$ and transcription start sites (TSS) is affected by training to a NOR task. One hour after training NF-kB is bound to its $\mathrm{kB}$ site in CaMKIII promoter but there is no change in nucleosome occupancy at this site compared to non-trained animals (Federman et al., 2013; Zalcman et al., 2018). Three hours after training nucleosome occupancy is increased in $\mathrm{kB}$ site, and it is decreased on TSS site, there is also an increase in CaMKIII transcription. Since nucleosome occupancy at specific regions has been proposed to disfavor protein binding (Bai and Morozov, 2010), the observation at $3 \mathrm{~h}$ suggests that NF-KB binding decreases while CaMKII $\delta$ transcription is enhanced. Seven days after training nucleosome occupancy at TSS is increased presumably decreasing the rate of gene expression. Finally, 20 days after, when memory retention is lost, nucleosome occupancy on TSS site becomes return to the level of non-trained animals. ${ }^{*} p<0.05 ;{ }^{* *} p<0.005 ;{ }^{* * *} p<0.0005$. 
related to memory processes, with HDAC4 being the most studied deacetylase subtype in neural plasticity and memory (Sando et al., 2012), and its role in this process evolutionarily conserved (Fitzsimons et al., 2013, p. 4; Reul, 2014; Hudson et al., 2015). Therefore, CaMKII $\delta$ may be regulating these proteins in order to promote sustained changes in the expression of genes necessary to maintain the memory trace. The second question is how might CaMKII $\delta$ sustain its gene expression? We propose that there is a feed-back mechanism in the nucleus, in which CaMKII $\delta$ phosphorylates HDAC4 and histone $\mathrm{H} 3$ to sustain its own expression over time. Since CaMKII $\delta$ mRNA expression returns to basal levels after 20 days, this feed-back mechanism may decay over time. This last assumption is in accordance with our finding that nucleosome occupancy at the camk2d transcription start site changed 7 days after training in an opposite manner to what was observed in an early phase (Zalcman et al., 2018).

\section{CaMKIl $\gamma$}

The $\gamma$ isoform is expressed in the brain of mammals, in cardiac tissue, in smooth muscle, liver, and cells of the immune system (Tobimatsu and Fujisawa, 1989; Bayer et al., 1999; Gangopadhyay et al., 2003). As with the other isoforms, CaMKII $\gamma$ can be spliced to different variants termed $\gamma \mathrm{A}$ to $\gamma \mathrm{H}$ (Hudmon and Schulman, 2002; Gangopadhyay et al., 2003). The $\gamma \mathrm{A}$ variant is brain specific

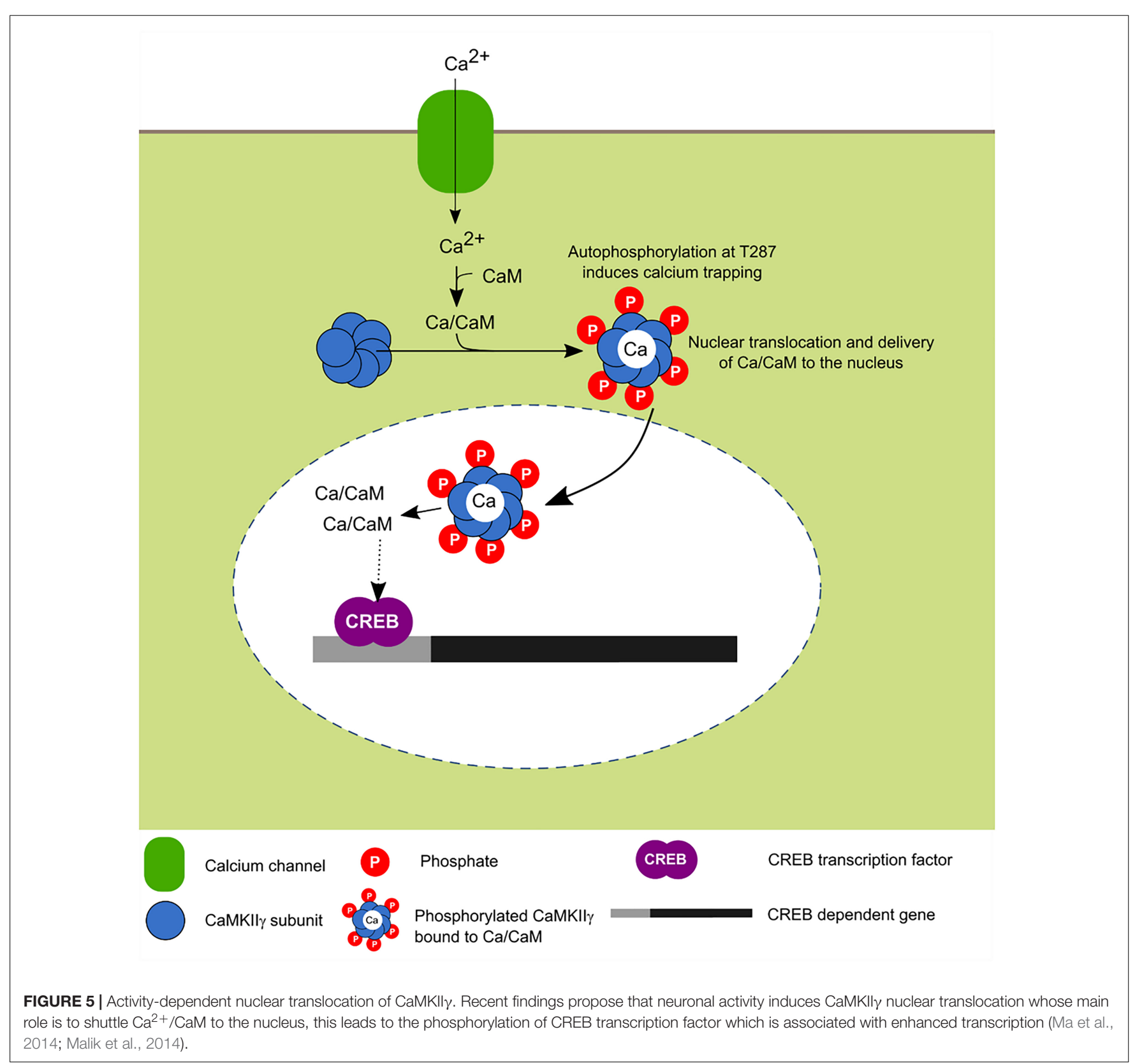


and contains the NLS, present in other CaMKII isoforms, thus can translocate to the nucleus by a mechanism similar to the one established for the other isoforms (Figure 5). Other variants, like $\gamma \mathrm{C}$, have also been shown to be expressed in neurons (Kamata et al., 2006).

In cultured neurons, it was recently shown that depolarization induces the translocation of this isoform to the nucleus and it has been postulated that its main function is to serve as a transport protein of the $\mathrm{Ca}^{2+} / \mathrm{CaM}$ complex to the nucleus in order to induce the signaling cascade dependent on this signal and activate CaM kinase families for the transcriptional regulation mediated in part by CREB (Ma et al., 2014).

\section{ROLE OF $\gamma$ ISOFORM IN MEMORY}

Few studies have been published showing a connection between this isoform and memory. In humans it has been shown that genetic variability around this gene affects performance in episodic memory tests (de Quervain and Papassotiropoulos, 2006) and intellectual capacity (de Ligt et al., 2012). CaMKII $\gamma$ KO mice have been recently developed. This animals showed learning deficits in Morris water maze and Radial arm maze, as well as impaired long-term memory in an inhibitory avoidance task (Cohen et al., 2018). These tasks are mainly hippocampaldependent, while inhibitory avoidance is also dependent on the amygdala. It should be noted, that learning curves were analyzed over consecutive days, and is therefore difficult to disentangle a learning deficit from a long-term memory storage deficit. Normal anxiety and locomotor activity were not affected in mutant animals compared to wild type littermates. They further demonstrated that these animals had decreased levels of nuclear CaM and performed different experiments to show that this was an effect of deficient CaMKII $\gamma$-dependent transport of CaM to the nucleus. Altogether these results show that CaMKII $\gamma$ is involved in spatial learning and long-term memory storage.

\section{CONCLUDING REMARKS AND FUTURE DIRECTIONS}

Although the key role of CaMKII in neural plasticity and memory have been stressed by decades of study since the initial discovery of its role in long-term potentiation (LTP), the specific role of each isoform in different subcellular compartment is still under investigation and required further analysis (Box 1). Recent findings suggest that each of the four isoforms play different roles and, in some cases, this role is not dependent on the enzymatic function. As was described earlier, the $\alpha$ isoform plays an important role associated with the PSD in dendritic spines of excitatory synapses, regulating receptor and channel functions as well as receptor trafficking. The $\beta$ isoform could have a non-enzymatic role in LTM consolidation, presumably by allowing CaMKII $\alpha$ translocation to the PSD. The activitydependent dissociation to F-actin seems to be important to regulate actin dynamics that may allow dendritic spine plasticity and synaptic reorganization. The main function of $\gamma$ isoform is
BOX 1 | Open questions on CaMKII isoforms in learning and memory.

Which is the subunit composition of endogenous CaMKII in the brain and how does this affect its location and function?

Little is known on the endogenous assembly of subunits and variants, how this affects the overall function and location of the enzyme and if this could be regulated by behavioral experience. Current evidence indicates that in forebrain, endogenous CaMKIl $\alpha$ forms homomers as well as heteromers with CaMKII $\beta$ (Brocke et al., 1999), and that the percentage of each subunit on the holoenzyme affects autophosphorylation rate and PSD translocation (Shen et al., 1998; Brocke et al., 1999; Shen and Meyer, 1999). Further studies are necessary to learn about the formation of heteromers with the other isoforms, $\delta$ and $\gamma$, as well as splicing variants composition.

What is the gene expression kinetics of the different isoforms during the different memory phases?

Much of the work on the role of CaMKII expression in learning and memory has been done using transgenic animals. Gene expression is a key molecular event in the formation and storage of long-lasting memories, therefore further studies on the expression of the different isoforms will help to provide insight not only on their role in learning and memory but also on the molecular mechanisms that underlie these processes.

What is the role of the different isoforms in pre-synaptic terminals and nucleus?

Most of the studies in CaMKII have focused on synaptic plasticity at the post-synaptic terminal (Coultrap and Bayer, 2012; Hell, 2014). However, learning and memory also requires modifications at the presynapses and changes in gene transcription. CaMKII has been shown to be present in both compartments. Thus, further studies on the localization and function of each isoform in these compartments are required.

attributed to a synapse-to-nucleus communication, transporting $\mathrm{Ca}^{2+}$ signaling to regulate gene expression that is essential for the neural plasticity involved in memory. Recent results support a key role of the $\delta$ isoform in memory persistence and maintenance by means of the sustained expression of its gene. The presence of CaMKII $\delta$ in the presynapses and in the nucleus is an important finding which deserves further study.

Beyond the individual role of each isoform, CaMKII is multimeric. The assembly of 6 and then 12 subunits into holoenzymes is an important structural feature that can regulate and modify the function and localization of the kinase. The mRNA of $\alpha$ isoform presents $3^{\prime}$ UTR sequences that target the messenger to dendrites, where it is translated locally. This confers the possibility of homomers formation. However, forebrain CaMKII consists mainly of heteromers and the holoenzyme can include subunits from the four CaMKII genes and the multiple splice variants of those genes. The presence of different subunits could regulate the localization of the holoenzyme. For instance, subunits containing NLS could confer the possibility of nuclear translocation but, at the same time, would co-assemble with cytosolic subunits that could possibly retard its translocation. The regulation of heteromers composition is an important issue that deserves further investigation in the role of this key protein kinase in memory.

\section{AUTHOR CONTRIBUTIONS}

GZ and AR proposed the subject, discussed, and wrote the manuscript. NF discussed and revised the manuscript. 


\section{FUNDING}

This work was supported by research grants from the National Agency of Scientific and Technological Promotion of Argentina (ANPCyT) PICT2015 1199.

\section{REFERENCES}

Ahmed, R., Zha, X., Green, S. H., and Dailey, M. E. (2006). Synaptic activity and F-actin coordinately regulate CaMKIIalpha localization to dendritic postsynaptic sites in developing hippocampal slices. Mol. Cell. Neurosci. 31, 37-51. doi: 10.1016/j.mcn.2005.08.020

Alberini, C. M. (2009). Transcription factors in long-term memory and synaptic plasticity. Physiol. Rev. 89, 121-145. doi: 10.1152/physrev.00017.2008

Awad, S., Al-Haffar, K. M. A., Marashly, Q., Quijada, P., Kunhi, M., Al-Yacoub, N., et al. (2015). Control of histone $\mathrm{H} 3$ phosphorylation by CaMKII $\delta$ in response to haemodynamic cardiac stress. J. Pathol. 235, 606-618. doi: 10.1002/path.4489

Bachstetter, A. D., Webster, S. J., Tu, T., Goulding, D. S., Haiech, J., Watterson, D. M., et al. (2014). Generation and behavior characterization of CaMKII $\beta$ knockout mice. PLoS One 9:e105191. doi: 10.1371/journal.pone.0105191

Bai, L., and Morozov, A. V. (2010). Gene regulation by nucleosome positioning. Trends Genet. 26, 476-483. doi: 10.1016/j.tig.2010.08.003

Bangaru, M. L. Y., Meng, J., Kaiser, D. J., Yu, H., Fischer, G., Hogan, Q. H., et al. (2015). Differential expression of CaMKII isoforms and overall kinase activity in rat dorsal root ganglia after injury. Neuroscience 300, 116-127. doi: 10.1016/j.neuroscience.2015.05.007

Bayer, K. U., Löhler, J., Schulman, H., and Harbers, K. (1999). Developmental expression of the CaM kinase II isoforms: ubiquitous gamma- and delta-CaM kinase II are the early isoforms and most abundant in the developing nervous system. Brain Res. Mol. Brain Res. 70, 147-154. doi: 10.1016/S0169-328X(99) 00131-X

Bennett, M. K., Erondu, N. E., and Kennedy, M. B. (1983). Purification and characterization of a calmodulin-dependent protein kinase that is highly concentrated in brain. J. Biol. Chem. 258, 12735-12744.

Berger, S. M., and Bartsch, D. (2014). The role of L-type voltage-gated calcium channels Cav1.2 and Cav1.3 in normal and pathological brain function. Cell Tissue Res. 357, 463-476. doi: 10.1007/s00441-014-1936-3

Blichenberg, A., Rehbein, M., Müller, R., Garner, C. C., Richter, D., and Kindler, S. (2001). Identification of a cis-acting dendritic targeting element in the mRNA encoding the alpha subunit of Ca2+/calmodulin-dependent protein kinase II. Eur. J. Neurosci. 13, 1881-1888. doi: 10.1046/j.0953-816x.2001.01565.x

Borgesius, N. Z., van Woerden, G. M., Buitendijk, G. H. S., Keijzer, N., Jaarsma, D., Hoogenraad, C. C., et al. (2011). $\beta$ CaMKII plays a nonenzymatic role in hippocampal synaptic plasticity and learning by targeting $\alpha$ CaMKII to synapses. J. Neurosci. 31, 10141-10148. doi: 10.1523/JNEUROSCI.5105-10.2011

Brocke, L., Chiang, L. W., Wagner, P. D., and Schulman, H. (1999). Functional implications of the subunit composition of neuronal CaM kinase II. J. Biol. Chem. 274, 22713-22722. doi: 10.1074/jbc.274.32.22713

Brocke, L., Srinivasan, M., and Schulman, H. (1995). Developmental and regional expression of multifunctional $\mathrm{Ca} 2+/$ calmodulin-dependent protein kinase isoforms in rat brain. J. Neurosci. 15, 6797-6808. doi: 10.1523/JNEUROSCI.1510-06797.1995

Buard, I., Coultrap, S. J., Freund, R. K., Lee, Y.-S., Dell'Acqua, M. L., Silva, A. J., et al. (2010). CaMKII "autonomy" is required for initiating but not for maintaining neuronal long-term information storage. J. Neurosci. 30, 8214-8220. doi: 10. 1523/JNEUROSCI.1469-10.2010

Cammarota, M., Bernabeu, R., Levi De Stein, M., Izquierdo, I., and Medina, J. H. (1998). Learning-specific, time-dependent increases in hippocampal Ca2+/calmodulin-dependent protein kinase II activity and AMPA GluR1 subunit immunoreactivity. Eur. J. Neurosci. 10, 2669-2676. doi: 10.1046/j.14609568.1998.00254.x

Cammarota, M., Bevilaqua, L. R. M., Viola, H., Kerr, D. S., Reichmann, B., Teixeira, V., et al. (2002). Participation of CaMKII in Neuronal Plasticity and Memory Formation. Cell. Mol. Neurobiol. 22, 259-267. doi: 10.1023/A: 1020763716886

\section{ACKNOWLEDGMENTS}

We would like to thank Dr. Joan Heller Brown for valuable discussion and Candela Medina for proofreading and helpful comments on the manuscript.

Chang, J.-Y., Parra-Bueno, P., Laviv, T., Szatmari, E. M., Lee, S.-J. R., and Yasuda, R. (2017). CaMKII autophosphorylation is necessary for optimal integration of ca2+ signals during LTP induction, but not maintenance. Neuron 94, 800808.e4. doi: 10.1016/j.neuron.2017.04.041

Cho, M. H., Cao, X., Wang, D., and Tsien, J. Z. (2007). Dentate gyrus-specific manipulation of $\beta$-Ca2+/calmodulin-dependent kinase II disrupts memory consolidation. Proc. Natl. Acad. Sci. U.S.A. 104, 16317-16322. doi: 10.1073/ pnas.0703344104

Cohen, S. M., Suutari, B., He, X., Wang, Y., Sanchez, S., Tirko, N. N., et al. (2018) Calmodulin shuttling mediates cytonuclear signaling to trigger experiencedependent transcription and memory. Nat. Commun. 9:2451. doi: 10.1038/ s41467-018-04705-8

Cook, S. G., Bourke, A. M., O’Leary, H., Zaegel, V., Lasda, E., Mize-Berge, J., et al. (2018). Analysis of the CaMKII $\alpha$ and $\beta$ splice-variant distribution among brain regions reveals isoform-specific differences in holoenzyme formation. Sci. Rep. 8:5448. doi: 10.1038/s41598-018-23779-4

Coultrap, S. J., and Bayer, K. U. (2012). CaMKII regulation in information processing and storage. Trends Neurosci. 35, 607-618. doi: 10.1016/j.tins.2012. 05.003

D’Amours, G., Bureau, G., Boily, M.-J., and Cyr, M. (2011). Differential gene expression profiling in the mouse brain during motor skill learning: focus on the striatum structure. Behav. Brain Res. 221, 108-117. doi: 10.1016/j.bbr.2011. 02.030

de la Fuente, V., Federman, N., Zalcman, G., Salles, A., Freudenthal, R., and Romano, A. (2015). NF- $\mathrm{B}$ transcription factor role in consolidation and reconsolidation of persistent memories. Front. Mol. Neurosci. 8:50. doi: 10.3389/ fnmol.2015.00050

de Ligt, J., Willemsen, M. H., van Bon, B. W. M., Kleefstra, T., Yntema, H. G., Kroes, T., et al. (2012). Diagnostic exome sequencing in persons with severe intellectual disability. N. Engl. J. Med. 367, 1921-1929. doi: 10.1056/ NEJMoa1206524

de Quervain, D. J.-F., and Papassotiropoulos, A. (2006). Identification of a genetic cluster influencing memory performance and hippocampal activity in humans. Proc. Natl. Acad. Sci. U.S.A. 103, 4270-4274. doi: 10.1073/pnas.0510212103

Donai, H., Nakamura, M., Sogawa, Y., Wang, J. K., Urushihara, M., and Yamauchi, T. (2000). Involvement of $\mathrm{Ca} 2+/$ calmodulin-dependent protein kinase II in neurite outgrowth induced by cAMP treatment and serum deprivation in a central nervous system cell line, CAD derived from rat brain. Neurosci. Lett. 293, 111-114. doi: 10.1016/S0304-3940(00)01500-7

Easley, C. A., Faison, M. O., Kirsch, T. L., Lee, J. A., Seward, M. E., and Tombes, R. M. (2006). Laminin activates CaMK-II to stabilize nascent embryonic axons. Brain Res. 1092, 59-68. doi: 10.1016/j.brainres.2006.03.099

Elgersma, Y., Fedorov, N. B., Ikonen, S., Choi, E. S., Elgersma, M., Carvalho, O. M., et al. (2002). Inhibitory autophosphorylation of CaMKII controls PSD association, plasticity, and learning. Neuron 36, 493-505. doi: 10.1016/S08966273(02)01007-3

Elgersma, Y., Sweatt, J. D., and Giese, K. P. (2004). Mouse genetic approaches to investigating calcium/calmodulin-dependent protein kinase II function in plasticity and cognition. J. Neurosci. 24, 8410-8415. doi: 10.1523/JNEUROSCI. 3622-04.2004

Erondu, N. E., and Kennedy, M. B. (1985). Regional distribution of type II $\mathrm{Ca} 2+/$ calmodulin-dependent protein kinase in rat brain. J. Neurosci. 5, 32703277. doi: 10.1523/JNEUROSCI.05-12-03270.1985

Faison, M. O., Perozzi, E. F., Caran, N., Stewart, J. K., and Tombes, R. M. (2002). Axonal localization of delta $\mathrm{Ca} 2+/$ calmodulin-dependent protein kinase II in developing P19 neurons. Int. J. Dev. Neurosci. 20, 585-592. doi: 10.1016/S07365748(02)00107-7

Federman, N., de la Fuente, V., Zalcman, G., Corbi, N., Onori, A., Passananti, C., et al. (2013). Nuclear factor $\kappa \mathrm{B}$-dependent histone acetylation is specifically 
involved in persistent forms of memory. J. Neurosci. 33, 7603-7614. doi: 10. 1523/JNEUROSCI.4181-12.2013

Federman, N., Zalcman, G., de la Fuente, V., Fustiñana, M. S., and Romano, A. (2014). Epigenetic mechanisms and memory strength: a comparative study. J. Physiol. Paris 108, 278-285. doi: 10.1016/j.jphysparis.2014.06.003

Fitzsimons, H. L., Schwartz, S., Given, F. M., and Scott, M. J. (2013). The histone deacetylase HDAC4 regulates long-term memory in Drosophila. PLoS One 8:e83903. doi: 10.1371/journal.pone.0083903

Frankland, P. W., Bontempi, B., Talton, L. E., Kaczmarek, L., and Silva, A. J. (2004), The involvement of the anterior cingulate cortex in remote contextual fear memory. Science 304, 881-883. doi: 10.1126/science.1094804

Frankland, P. W., O’Brien, C., Ohno, M., Kirkwood, A., and Silva, A. J. (2001). Alpha-CaMKII-dependent plasticity in the cortex is required for permanent memory. Nature 411, 309-313. doi: 10.1038/35077089

Gaertner, T. R., Kolodziej, S. J., Wang, D., Kobayashi, R., Koomen, J. M., Stoops, J. K., et al. (2004). Comparative analyses of the three-dimensional structures and enzymatic properties of $\alpha, \beta, \gamma$, and $\delta$ isoforms of Ca2+-calmodulindependent protein kinase II. J. Biol. Chem. 279, 12484-12494. doi: 10.1074/jbc. M313597200

Gangopadhyay, S. S., Barber, A. L., Gallant, C., Grabarek, Z., Smith, J. L., and Morgan, K. G. (2003). Differential functional properties of calmodulindependent protein kinase IIgamma variants isolated from smooth muscle. Biochem. J. 372, 347-357. doi: 10.1042/bj20030015

Giese, K. P., Fedorov, N. B., Filipkowski, R. K., and Silva, A. J. (1998). Autophosphorylation at Thr286 of the alpha calcium-calmodulin kinase II in LTP and learning. Science 279, 870-873. doi: 10.1126/science.279.5352.870

Giese, K. P., and Mizuno, K. (2013). The roles of protein kinases in learning and memory. Learn. Mem. Cold Spring Harb. N. 20, 540-552. doi: 10.1101/lm. 028449.112

Gray, C. B. B., and Heller Brown, J. (2014). CaMKIIdelta subtypes: localization and function. Front. Pharmacol. 5:15. doi: 10.3389/fphar.2014.00015

Gray, C. B. B., Suetomi, T., Xiang, S., Mishra, S., Blackwood, E. A., Glembotski, C. C., et al. (2017). CaMKII subtypes differentially regulate infarct formation following ex vivo myocardial ischemia/reperfusion through NF- $\kappa B$ and TNF- $\alpha$. J. Mol. Cell. Cardiol. 103, 48-55. doi: 10.1016/j.yjmcc.2017.01.002

Griffith, L. C., Lu, C. S., and Sun, X. X. (2003). CaMKII, an enzyme on the move: regulation of temporospatial localization. Mol. Interv. 3, 386-403. doi: 10.1124/mi.3.7.386

Hanson, P. I., Kapiloff, M. S., Lou, L. L., Rosenfeld, M. G., and Schulman, H. (1989). Expression of a multifunctional Ca2+/calmodulin-dependent protein kinase and mutational analysis of its autoregulation. Neuron 3, 59-70. doi: 10.1016/0896-6273(89)90115-3

Hanson, P. I., Meyer, T., Stryer, L., and Schulman, H. (1994). Dual role of calmodulin in autophosphorylation of multifunctional CaM kinase may underlie decoding of calcium signals. Neuron 12, 943-956. doi: 10.1016/08966273(94)90306-9

Heist, E. K., Srinivasan, M., and Schulman, H. (1998). Phosphorylation at the nuclear localization signal of $\mathrm{Ca} 2+/$ calmodulin-dependent protein kinase II blocks its nuclear targeting. J. Biol. Chem. 273, 19763-19771. doi: 10.1074/jbc. 273.31.19763

Hell, J. W. (2014). CaMKII: claiming center stage in postsynaptic function and organization. Neuron 81, 249-265. doi: 10.1016/j.neuron.2013.12.024

Hoffman, L., Farley, M. M., and Waxham, M. N. (2013). Calcium-calmodulindependent protein kinase II isoforms differentially impact the dynamics and structure of the actin cytoskeleton. Biochemistry 52, 1198-1207. doi: 10.1021/ bi3016586

Hotulainen, P., and Hoogenraad, C. C. (2010). Actin in dendritic spines: connecting dynamics to function. J. Cell Biol. 189, 619-629. doi: 10.1083/jcb. 201003008

Hsieh, C., Tsokas, P., Serrano, P., Hernandez, I., Tian, D., Cottrell, J. E., et al. (2016) Persistent increased $\mathrm{PKM} \zeta$ in long-term and remote spatial memory. Neurobiol. Learn. Mem. 138, 135-144. doi: 10.1016/j.nlm.2016.07.008

Hudmon, A., and Schulman, H. (2002). Neuronal CA2+/calmodulin-dependent protein kinase II: the role of structure and autoregulation in cellular function. Annu. Rev. Biochem. 71, 473-510. doi: 10.1146/annurev.biochem.71.110601. 135410

Hudson, G. M., Watson, P. J., Fairall, L., Jamieson, A. G., and Schwabe, J. W. R. (2015). Insights into the Recruitment of Class IIa Histone Deacetylases
(HDACs) to the SMRT/NCoR transcriptional repression complex. J. Biol. Chem 290, 18237-18244. doi: 10.1074/jbc.M115.661058

Igaz, L. M., Bekinschtein, P., Izquierdo, I., and Medina, J. H. (2004). One-trial aversive learning induces late changes in hippocampal CaMKIIalpha, Homer 1a, Syntaxin 1a and ERK2 protein levels. Brain Res. Mol. Brain Res. 132, 1-12. doi: 10.1016/j.molbrainres.2004.08.016

Irvine, E. E., Vernon, J., and Giese, K. P. (2005). $\alpha$ CaMKII autophosphorylation contributes to rapid learning but is not necessary for memory. Nat. Neurosci. 8 , 411-412. doi: 10.1038/nn1431

Irvine, E. E., von Hertzen, L. S. J., Plattner, F., and Giese, K. P. (2006). alphaCaMKII autophosphorylation: a fast track to memory. Trends Neurosci. 29, 459-465. doi: 10.1016/j.tins.2006.06.009

Johnson, L. D., Willoughby, C. A., Burke, S. H., Paik, D. S., Jenkins, K. J., and Tombes, R. M. (2000). delta $\mathrm{Ca}(2+) /$ Calmodulin-dependent protein kinase II isozyme-specific induction of neurite outgrowth in P19 embryonal carcinoma cells. J. Neurochem. 75, 2380-2391. doi: 10.1046/j.1471-4159.2000.0752 380.x

Jourdain, P., Fukunaga, K., and Muller, D. (2003). Calcium/calmodulin-dependent protein kinase II contributes to activity-dependent filopodia growth and spine formation. J. Neurosci. 23, 10645-10649. doi: 10.1523/JNEUROSCI.23-3310645.2003

Jovanovic, J. N., Sihra, T. S., Nairn, A. C., Hemmings, H. C., Greengard, P., and Czernik, A. J. (2001). Opposing changes in phosphorylation of specific sites in synapsin I during $\mathrm{Ca} 2+$-dependent glutamate release in isolated nerve terminals. J. Neurosci. 21, 7944-7953. doi: 10.1523/JNEUROSCI.21-20-07944. 2001

Kamata, A., Takeuchi, Y., and Fukunaga, K. (2006). Identification of the isoforms of $\mathrm{Ca} 2+/$ calmodulin-dependent protein kinase II and expression of brain-derived neurotrophic factor mRNAs in the substantia nigra. J. Neurochem. 96, 195-203. doi: $10.1111 / j .1471-4159.2005 .03531 . x$

Kim, S., and Kaang, B.-K. (2017). Epigenetic regulation and chromatin remodeling in learning and memory. Exp. Mol. Med. 49:e281. doi: 10.1038/emm.2016.140

Lamprecht, R. (2014). The actin cytoskeleton in memory formation. Prog. Neurobiol. 117, 1-19. doi: 10.1016/j.pneurobio.2014.02.001

Lee, S.-J. R., Escobedo-Lozoya, Y., Szatmari, E. M., and Yasuda, R. (2009). Activation of CaMKII in single dendritic spines during long-term potentiation. Nature 458, 299-304. doi: 10.1038/nature07842

Li, Q., Rothkegel, M., Xiao, Z. C., Abraham, W. C., Korte, M., and Sajikumar, S. (2012). Making synapses strong: metaplasticity prolongs associativity of longterm memory by switching synaptic tag mechanisms. Cereb. Cortex 24, 353363. doi: 10.1093/cercor/bhs315

Lin, Y.-C., and Redmond, L. (2008). CaMKII $\beta$ binding to stable F-actin in vivo regulates F-actin filament stability. Proc. Natl. Acad. Sci. U.S.A. 105, 1579115796. doi: $10.1073 /$ pnas. 0804399105

Lisman, J., Schulman, H., and Cline, H. (2002). The molecular basis of CaMKII function in synaptic and behavioural memory. Nat. Rev. Neurosci. 3, 175-190. doi: $10.1038 / \mathrm{nrn} 753$

Lisman, J., Yasuda, R., and Raghavachari, S. (2012). Mechanisms of CaMKII action in long-term potentiation. Nat. Rev. Neurosci. 13, 169-182. doi: 10.1038/ nrn3192

Liu, X., and Jones, E. G. (1997). Alpha isoform of calcium-calmodulin dependent protein kinase II (CAM II kinase-alpha) restricted to excitatory synapses in the CA1 region of rat hippocampus. Neuroreport 8, 1475-1479. doi: 10.1097/ 00001756-199704140-00030

Liu, X. B., and Jones, E. G. (1996). Localization of alpha type II calcium calmodulindependent protein kinase at glutamatergic but not gamma-aminobutyric acid (GABAergic) synapses in thalamus and cerebral cortex. Proc. Natl. Acad. Sci. U.S.A. 93, 7332-7336. doi: 10.1073/pnas.93.14.7332

Liu, X.-B., and Murray, K. D. (2012). Neuronal excitability and calcium/calmodulin-dependent protein kinase type II: location, location, location. Epilepsia 53(Suppl. 1), 45-52. doi: 10.1111/j.1528-1167.2012.03474.x

Lu, F.-M., and Hawkins, R. D. (2006). Presynaptic and postsynaptic Ca2+ and CamKII contribute to long-term potentiation at synapses between individual CA3 neurons. Proc. Natl. Acad. Sci. U.S.A. 103, 4264-4269. doi: 10.1073/pnas. 0508162103

Lucchesi, W., Mizuno, K., and Giese, K. P. (2011). Novel insights into CaMKII function and regulation during memory formation. Brain Res. Bull. 85, 2-8. doi: 10.1016/j.brainresbull.2010.10.009 
Ma, H., Groth, R. D., Cohen, S. M., Emery, J. F., Li, B.-X., Hoedt, E., et al. (2014). $\gamma \mathrm{CaMKII}$ shuttles $\mathrm{Ca} 2+/ \mathrm{CaM}$ to the nucleus to trigger CREB phosphorylation and gene expression. Cell 159, 281-294. doi: 10.1016/j.cell.2014.09.019

Malik, Z. A., Stein, I. S., Navedo, M. F., and Hell, J. W. (2014). Mission CaMKII $\gamma$ : shuttle calmodulin from membrane to nucleus. Cell 159, 235-237. doi: 10.1016/ j.cell.2014.09.023

Mayer, P., Möhlig, M., Idlibe, D., and Pfeiffer, A. (1995). Novel and uncommon isoforms of the calcium sensing enzyme calcium/calmodulin dependent protein kinase II in heart tissue. Basic Res. Cardiol. 90, 372-379. doi: 10.1007/ BF00788498

Mayer, P., Möhlig, M., Schatz, H., and Pfeiffer, A. (1993). New isoforms of multifunctional calcium/calmodulin-dependent protein kinase II. FEBS Lett. 333, 315-318. doi: 10.1016/0014-5793(93)80678-N

Mayford, M., Baranes, D., Podsypanina, K., and Kandel, E. R. (1996). The $3^{\prime}$ untranslated region of CaMKII alpha is a cis-acting signal for the localization and translation of mRNA in dendrites. Proc. Natl. Acad. Sci. U.S.A. 93, 13250-13255. doi: 10.1073/pnas.93.23.13250

Miller, S., Yasuda, M., Coats, J. K., Jones, Y., Martone, M. E., and Mayford, M. (2002). Disruption of dendritic translation of CaMKIIalpha impairs stabilization of synaptic plasticity and memory consolidation. Neuron 36, 507-519. doi: 10.1016/S0896-6273(02)00978-9

Moncada, D., Ballarini, F., Martinez, M. C., Frey, J. U., and Viola, H. (2011). Identification of transmitter systems and learning tag molecules involved in behavioral tagging during memory formation. Proc. Natl. Acad. Sci. U.S.A. 108, 12931-12936. doi: 10.1073/pnas.1104495108

Mori, Y., Imaizumi, K., Katayama, T., Yoneda, T., and Tohyama, M. (2000). Two cis-acting elements in the $3^{\prime}$ untranslated region of alpha-CaMKII regulate its dendritic targeting. Nat. Neurosci. 3, 1079-1084. doi: 10.1038/80591

Morris, R. G. M. (2013). NMDA receptors and memory encoding. Neuropharmacology 74, 32-40. doi: 10.1016/j.neuropharm.2013.04.014

Murakoshi, H., Shin, M. E., Parra-Bueno, P., Szatmari, E. M., Shibata, A. C. E., and Yasuda, R. (2017). Kinetics of Endogenous CaMKII required for synaptic plasticity revealed by optogenetic kinase inhibitor. Neuron 94:690. doi: 10.1016/ j.neuron.2017.04.027

Néant-Fery, M., Pérès, E., Nasrallah, C., Kessner, M., Gribaudo, S., Greer, C., et al. (2012). A role for dendritic translation of CaMKII $\alpha$ mRNA in olfactory plasticity. PLoS One 7:e40133. doi: 10.1371/journal.pone.0040133

Ninan, I., and Arancio, O. (2004). Presynaptic CaMKII is necessary for synaptic plasticity in cultured hippocampal neurons. Neuron 42, 129-141. doi: 10.1016/ S0896-6273(04)00143-6

Ojuka, E. O., Goyaram, V., and Smith, J. A. H. (2012). The role of CaMKII in regulating GLUT4 expression in skeletal muscle. Am. J. Physiol. Endocrinol. Metab. 303, E322-E331. doi: 10.1152/ajpendo.00091.2012

Okamoto, K.-I., Narayanan, R., Lee, S. H., Murata, K., and Hayashi, Y. (2007). The role of CaMKII as an F-actin-bundling protein crucial for maintenance of dendritic spine structure. Proc. Natl. Acad. Sci. U.S.A. 104, 6418-6423. doi: 10.1073/pnas.0701656104

Okuno, H., Akashi, K., Ishii, Y., Yagishita-Kyo, N., Suzuki, K., Nonaka, M., et al. (2012). Inverse synaptic tagging of inactive synapses via dynamic interaction of Arc/Arg3.1 with CaMKIIß. Cell 149, 886-898. doi: 10.1016/j.cell.2012.02.062

O'Leary, H., Lasda, E., and Bayer, K. U. (2006). CaMKII $\beta$ association with the actin cytoskeleton is regulated by alternative splicing. Mol. Biol. Cell 17, 4656-4665. doi: 10.1091/mbc.E06-03-0252

Redondo, R. L., Okuno, H., Spooner, P. A., Frenguelli, B. G., Bito, H., and Morris, R. G. M. (2010). Synaptic tagging and capture: differential role of distinct calcium/calmodulin kinases in protein synthesis-dependent long-term potentiation. J. Neurosci. 30, 4981-4989. doi: 10.1523/JNEUROSCI.3140-09. 2010

Reul, J. M. H. M. (2014). Making memories of stressful events: a journey along epigenetic, gene transcription, and signaling pathways. Front. Psychiatry 5:5. doi: $10.3389 /$ fpsyt.2014.00005

Romano, A. (2012). "NF-kB transcription factor: a model for the study of transcription regulation in memory consolidation, reconsolidation and extinction," in Transcription Factors CREB and NF- $B$ : Involvement in Synaptic Plasticity and Memory Formation, ed. B. C. Albensi (Sharjah: Bentham Science Publishers), 97-112.

Rossetti, T., Banerjee, S., Kim, C., Leubner, M., Lamar, C., Gupta, P., et al. (2017). Memory erasure experiments indicate a critical role of CaMKII in memory storage. Neuron 96, 207-216.e2. doi: 10.1016/j.neuron.2017. 09.010

Sajikumar, S., Navakkode, S., and Frey, J. U. (2007). Identification of compartmentand process-specific molecules required for "synaptic tagging" during long-term potentiation and long-term depression in hippocampal CA1. J. Neurosci. 27, 5068-5080. doi: 10.1523/JNEUROSCI.4940-06.2007

Sanabria, H., Swulius, M. T., Kolodziej, S. J., Liu, J., and Waxham, M. N. (2009). \{beta\}CaMKII regulates actin assembly and structure. J. Biol. Chem. 284, 97709780. doi: 10.1074/jbc.M809518200

Sando, R., Gounko, N., Pieraut, S., Liao, L., Yates, J., and Maximov, A. (2012). HDAC4 governs a transcriptional program essential for synaptic plasticity and memory. Cell 151, 821-834. doi: 10.1016/j.cell.2012.09.037

Sanhueza, M., and Lisman, J. (2013). The CaMKII/NMDAR complex as a molecular memory. Mol. Brain 6:10. doi: 10.1186/1756-6606-6-10

Schulman, H., Heist, K., and Srinivasan, M. (1995). Decoding Ca2+ signals to the nucleus by multifunctional CaM kinase. Prog. Brain Res. 105, 95-104. doi: 10.1016/S0079-6123(08)63287-2

Schworer, C. M., Rothblum, L. I., Thekkumkara, T. J., and Singer, H. A. (1993). Identification of novel isoforms of the delta subunit of $\mathrm{Ca} 2+/$ calmodulindependent protein kinase II. Differential expression in rat brain and aorta. J. Biol. Chem. 268, 14443-14449.

Shema, R., Haramati, S., Ron, S., Hazvi, S., Chen, A., Sacktor, T. C., et al. (2011). Enhancement of consolidated long-term memory by overexpression of protein kinase $M \zeta$ in the neocortex. Science 331, 1207-1210. doi: 10.1126/science. 1200215

Shen, K., and Meyer, T. (1999). Dynamic control of CaMKII translocation and localization in hippocampal neurons by NMDA receptor stimulation. Science 284, 162-166. doi: 10.1126/science.284.5411.162

Shen, K., Teruel, M. N., Subramanian, K., and Meyer, T. (1998). CaMKIIbeta functions as an F-actin targeting module that localizes CaMKIIalpha/beta heterooligomers to dendritic spines. Neuron 21, 593-606. doi: 10.1016/S08966273(00)80569-3

Shioda, N., Sawai, M., Ishizuka, Y., Shirao, T., and Fukunaga, K. (2015). Nuclear translocation of Calcium/Calmodulin-dependent Protein Kinase II $\delta 3$ Promoted by Protein Phosphatase-1 Enhances Brain-derived Neurotrophic Factor Expression in Dopaminergic Neurons. J. Biol. Chem. 290, 21663-21675. doi: 10.1074/jbc.M115.664920

Silva, A. J., Paylor, R., Wehner, J. M., and Tonegawa, S. (1992a). Impaired spatial learning in alpha-calcium-calmodulin kinase II mutant mice. Science 257, 206-211. doi: 10.1126/science.1321493

Silva, A. J., Rosahl, T. W., Chapman, P. F., Marowitz, Z., Friedman, E., Frankland, P. W., et al. (1996). Impaired learning in mice with abnormal short-lived plasticity. Curr. Biol. 6, 1509-1518. doi: 10.1016/S0960-9822(96)00756-7

Silva, A. J., Stevens, C. F., Tonegawa, S., and Wang, Y. (1992b). Deficient hippocampal long-term potentiation in alpha-calcium-calmodulin kinase II mutant mice. Science 257, 201-206.

Srinivasan, M., Edman, C. F., and Schulman, H. (1994). Alternative splicing introduces a nuclear localization signal that targets multifunctional CaM kinase to the nucleus. J. Cell Biol. 126, 839-852. doi: 10.1083/jcb.126.4.839

Szabó, E. C., Manguinhas, R., and Fonseca, R. (2016). The interplay between neuronal activity and actin dynamics mimic the setting of an LTD synaptic tag. Sci. Rep. 6:33685. doi: 10.1038/srep33685

Takeuchi, Y., Yamamoto, H., Matsumoto, K., Kimura, T., Katsuragi, S., Miyakawa, T., et al. (1999). Nuclear localization of the delta subunit of $\mathrm{Ca} 2+/$ calmodulin-dependent protein kinase II in rat cerebellar granule cells. J. Neurochem. 72, 815-825. doi: 10.1046/j.1471-4159.1999.072 0815.x

Tan, S.-E., and Liang, K.-C. (1996). Spatial learning alters hippocampal calcium/calmodulin-dependent protein kinase II activity in rats. Brain Res. 711 , 234-240. doi: 10.1016/0006-8993(95)01411-X

Tobimatsu, T., and Fujisawa, H. (1989). Tissue-specific expression of four types of rat calmodulin-dependent protein kinase II mRNAs. J. Biol. Chem. 264, 17907-17912.

Tombes, R. M., Faison, M. O., and Turbeville, J. M. (2003). Organization and evolution of multifunctional $\mathrm{Ca}(2+) / \mathrm{CaM}$-dependent protein kinase genes. Gene 322, 17-31. doi: 10.1016/j.gene.2003.08.023

van Woerden, G. M., Hoebeek, F. E., Gao, Z., Nagaraja, R. Y., Hoogenraad, C. C., Kushner, S. A., et al. (2009). betaCaMKII controls the direction of plasticity at 
parallel fiber-Purkinje cell synapses. Nat. Neurosci. 12, 823-825. doi: 10.1038/ nn.2329

Wang, H., Shimizu, E., Tang, Y.-P., Cho, M., Kyin, M., Zuo, W., et al. (2003). Inducible protein knockout reveals temporal requirement of CaMKII reactivation for memory consolidation in the brain. Proc. Natl. Acad. Sci. U.S.A. 100, 4287-4292. doi: 10.1073/pnas.0636870100

Wang, Q., Yin, P., Yu, B., Zhao, Z., Richter-Levin, G., Yu, L., et al. (2017). Downregulation of dorsal striatal $\alpha$ CaMKII causes striatum-related cognitive and synaptic disorders. Exp. Neurol. 298, 112-121. doi: 10.1016/j.expneurol.2017. 09.004

Wang, Z.-W. (2008). Regulation of synaptic transmission by presynaptic CaMKII and BK channels. Mol. Neurobiol. 38, 153-166. doi: 10.1007/s12035-008-8039-7

Wu, X., and McMurray, C. T. (2001). Calmodulin Kinase II Attenuation of Gene Transcription by Preventing cAMP Response Element-binding Protein (CREB) Dimerization and Binding of the CREB-binding Protein. J. Biol. Chem. 276, 1735-1741. doi: 10.1074/jbc.M006727200

Xiao, H.-S., Huang, Q.-H., Zhang, F.-X., Bao, L., Lu, Y.-J., Guo, C., et al. (2002). Identification of gene expression profile of dorsal root ganglion in the rat peripheral axotomy model of neuropathic pain. Proc. Natl. Acad. Sci. U.S.A. 99, 8360-8365. doi: 10.1073/pnas.122231899

Yamagata, Y., Kobayashi, S., Umeda, T., Inoue, A., Sakagami, H., Fukaya, M., et al. (2009). Kinase-dead knock-in mouse reveals an essential role of kinase activity of $\mathrm{Ca} 2+/$ calmodulin-dependent protein kinase II $\alpha$ in dendritic spine enlargement, long-term potentiation, and learning. J. Neurosci. 29, 7607-7618. doi: 10.1523/JNEUROSCI.0707-09.2009

Yamasaki, N., Maekawa, M., Kobayashi, K., Kajii, Y., Maeda, J., Soma, M., et al. (2008). Alpha-CaMKII deficiency causes immature dentate gyrus, a novel candidate endophenotype of psychiatric disorders. Mol. Brain 1:6. doi: 10.1186/ 1756-6606-1-6

Yasuda, M., and Mayford, M. R. (2006). CaMKII activation in the entorhinal cortex disrupts previously encoded spatial memory. Neuron 50, 309-318. doi: 10.1016/j.neuron.2006.03.035

Yin, P., Xu, H., Wang, Q., Wang, J., Yin, L., Xu, M., et al. (2017). Overexpression of $\beta$ CaMKII impairs behavioral flexibility and NMDAR-dependent long-term depression in the dentate gyrus. Neuropharmacology 116, 270-287. doi: 10. 1016/j.neuropharm.2016.12.013
Zalcman, G., Federman, N., Fiszbein, A., de la Fuente, V., Ameneiro, L., Schor, I., et al. (2018). Sustained CaMKII delta gene expression is specifically required for long-lasting memories in mice. Mol. Neurobiol. doi: 10.1007/s12035-0181144-3 [Epub ahead of print].

Zhang, M., Shan, H., Gu, Z., Wang, D., Wang, T., Wang, Z., et al. (2012). Increased expression of calcium/calmodulin-dependent protein kinase type II subunit delta after rat traumatic brain injury. J. Mol. Neurosci. 46, 631-643. doi: 10.1007/ s12031-011-9651-y

Zhang, T., and Brown, J. H. (2004). Role of Ca2+/calmodulin-dependent protein kinase II in cardiac hypertrophy and heart failure. Cardiovasc. Res. 63, 476-486. doi: 10.1016/j.cardiores.2004.04.026

Zhang, T., Johnson, E. N., Gu, Y., Morissette, M. R., Sah, V. P., Gigena, M. S., et al. (2002). The cardiac-specific nuclear delta(B) isoform of $\mathrm{Ca} 2+/$ calmodulindependent protein kinase II induces hypertrophy and dilated cardiomyopathy associated with increased protein phosphatase 2A activity. J. Biol. Chem. 277, 1261-1267. doi: 10.1074/jbc.M108525200

Zhang, T., Kohlhaas, M., Backs, J., Mishra, S., Phillips, W., Dybkova, N., et al. (2007). CaMKIIdelta isoforms differentially affect calcium handling but similarly regulate HDAC/MEF2 transcriptional responses. J. Biol. Chem. 282, 35078-35087. doi: 10.1074/jbc.M707083200

Zhang, T., Maier, L. S., Dalton, N. D., Miyamoto, S., Ross, J., Bers, D. M., et al. (2003). The deltaC isoform of CaMKII is activated in cardiac hypertrophy and induces dilated cardiomyopathy and heart failure. Circ. Res. 92, 912-919. doi: 10.1161/01.RES.0000069686.31472.C5

Conflict of Interest Statement: The authors declare that the research was conducted in the absence of any commercial or financial relationships that could be construed as a potential conflict of interest.

Copyright (c) 2018 Zalcman, Federman and Romano. This is an open-access article distributed under the terms of the Creative Commons Attribution License (CC BY). The use, distribution or reproduction in other forums is permitted, provided the original author(s) and the copyright owner(s) are credited and that the original publication in this journal is cited, in accordance with accepted academic practice. No use, distribution or reproduction is permitted which does not comply with these terms. 